OPEN ACCESS

Edited by:

Mette Søndergaard Deleuran

Aarhus University Hospital, Denmark

Reviewed by:

Vijaykumar Patra,

Medical University of Graz, Austria

Irina Khamaganova,

Pirogov Russian National Research

Medical University, Russia

*Correspondence:

Emilie Brenaut

emilie.brenaut@chu-brest.fr

Specialty section:

This article was submitted to

Dermatology,

a section of the journal

Frontiers in Medicine

Received: 09 November 2018

Accepted: 31 January 2019

Published: 20 February 2019

Citation:

Brenaut E, Misery L and Taieb C (2019) Sensitive Skin in the Indian

Population: An Epidemiological

Approach. Front. Med. 6:29.

doi: 10.3389/fmed.2019.00029

\section{Sensitive Skin in the Indian Population: An Epidemiological Approach}

\author{
Emilie Brenaut ${ }^{1,2 *}$, Laurent Misery ${ }^{1,2}$ and Charles Taieb ${ }^{3,4}$ \\ ${ }^{1}$ Department of Dermatology, University Hospital of Brest, Brest, France, ${ }^{2}$ Université de Bretagne Occidentale, LIEN, Brest, \\ France, ${ }^{3}$ EMMA, Direction Scientifique, Fontenay sous Bois, France, ${ }^{4}$ Hôpital Necker Enfants Malades, Santé Publique, \\ Paris, France
}

Sensitive skin is a very frequent condition, the prevalence of this syndrome has been studied in different countries in Europe, in United States and in Japan. The aim of the study was to evaluate the epidemiology of sensitive skin in the Indian population, like this has never been studied in this country. A representative nationwide sample of the Indian population aged 15 and over was selected. Individuals were selected as per the quota method (based on sex, age, householder profession, rural/urban location, and region). In total, $27.9 \%$ of men and $36.7 \%$ of women declared having "sensitive" or "very sensitive" skin. The difference between the 2 sexes was very significant. Of these, $5.1 \%$ of men and $7.2 \%$ of women reported having "very sensitive" skin. The subjects complaining about "sensitive" or "very sensitive" skin were 2-4 times more likely to declare suffering from atopic dermatitis, acne, psoriasis, or vitiligo. They were 2 to 3 times more reactive to climatic factors, environmental factors, cosmetics and food intake. In conclusion, although less frequently reported than in other countries, sensitive skin is a frequent condition in India, affecting about one third of the population.

Keywords: sensitive skin, reactive skin, India, epidemiological study, phone survey, skin disorder, environmental factors, cosmetics

\section{INTRODUCTION}

The concept of sensitive skin was introduced by Frosch (1) and Thiers (2). Sensitive skin is characterized by the occurrence of sensations of tingling, prickling, heat, burning, pain, or itching, and occasionally by erythema in response to multiple physical (UV radiation, heat, cold, or wind), chemical (cosmetics, soaps, pollution, or water), psychological (stress), and/or hormonal (menstrual cycle) factors that should not provoke such sensations (3-6). Sensitive skin is also called reactive, hyper-reactive, intolerant or irritable skin. The term "sensitive skin" mainly refers to facial skin, but this condition can also affect other areas of the body, such as the hands, scalp, or genital area (6-8).

The first epidemiological study of sensitive skin was conducted in the United Kingdom in 2001 (7); then, studies were conducted in many countries throughout the world, including Belgium, China, France, Germany, Greece, Italy, Portugal, Spain, Switzerland, the United States of America, Brazil, Japan, and Russia (8-13). These studies used similar methodologies based on surveys of samples of the population aged 15 years and older. It is very important to obtain data on sensitive skin in different countries and there was no data in India.

The aim of the present study was to perform the first epidemiological study on sensitive skin in India. 


\section{PATIENTS AND METHODS}

As in previous studies (8-13), questionnaires were administered by CSA Santé (CSA Health Institute) and the same methodology was used. Data were collected between April and May.

A sample of 3,012 individuals was selected based on criteria that allow representation of the Indian population aged 15 and older. The participants were selected by the quota method (based on gender, age, occupation of the family head, agglomeration level, and region). Systematic monitoring of interviews was conducted with a repeat call to $20 \%$ of those interviewed. In case this process could lead to a different outcome of any type, even for only one survey, all interviews conducted by the same interviewer were double-checked by another individual. No error was detected. Interviews were conducted in English or local languages: Hindi, Marathi, Gujarati, Bengali, or Tamil.

The first part of the questionnaire was related to demographics (geographical area, age, gender, and social status) and to skin type. The second part addressed facial skin sensitivity. The subjects were requested to rate their skin as "very sensitive," "sensitive," "slightly sensitive," or "not sensitive." The interviewees responded to an open question regarding their perception of the onset of tingling, burning or irritation in the presence of different factors, such as emotional stimuli, cold, heat, sun exposure, cosmetics, dry air, air-conditioning, water, air pollution, and variations in temperature. The participants were also asked if they had ever suffered from rashes without an apparent cause, if their facial skin was easily irritated, if they had visited a dermatologist during the previous year, and whether they had any skin diseases.

To characterize sensitive skin in the Indian population, the characteristics of the subjects with "sensitive" or "very sensitive" skin (the "sensitive skin" group) were compared with those of the subjects having "not very sensitive" or "not sensitive at all" skin ("non-sensitive skin" group).

Quantitative variables were compared between groups with Student's $t$-test (when there were two groups to compare) or ANOVA (when there were more than two groups to compare). When the conditions for the application of these tests were not met, the Wilcoxon and Kruskal-Wallis non-parametric tests were performed. Categorical variables were compared with an appropriate test, with Fisher's test used if the conditions were not completely met. Statistical analyses were performed with SAS software version 8.2 (SAS Institute).

Ethical review and approval were not required for this study in accordance with the local legislation and institutional requirements.

\section{RESULTS}

\section{Sensitive Skin and Demographic Data}

In total, $27.9 \%$ of men and $36.7 \%$ of women reported having "sensitive" or "very sensitive" skin (Figure 1). The difference between the 2 sexes was significant (Student's $t$-test, $p<0.001$ ). Of these, $5.5 \%$ of men and $8.2 \%$ of women reported having "very sensitive skin."
We detected significant differences in skin sensitivity according to age (Figure 2). Indeed, younger subjects (between 15 and 44 years old) more frequently reported sensitive skin than older subjects (over 45 years old) did (32.4 vs. $24.2 \%$, $p<0.001)$. The overall non-response rate was approximately $0.2 \%$ for men and women. This rate was higher in older subjects $(0.9 \%$ in subjects over 60 years old vs. $0.0 \%$ in subjects between 30 and 59 years old vs. $0.1 \%$ in subjects under 29 years old). The non-response rate suggested that the term "sensitive skin" had meaning for the majority of the sample of the Indian population.

\section{Sensitive Skin and Skin Disorders}

An evaluation of the frequency of various dermatoses showed differences between the 2 groups. The subjects in the "sensitive skin" group were 3 times more likely to declare suffering from a dermatosis (44.9 vs. 15.0\%). Indeed, the subjects complaining about "sensitive" skin were 2-4 times more likely to report atopic dermatitis, acne, psoriasis, vitiligo, rosacea, or contact dermatitis compared with the subjects in the "non-sensitive skin" group (Figure 3).

A history of atopic dermatitis or eczema in the childhood was more frequent in the subjects in the "sensitive skin" group (11.8 vs. $6.3 \%, p<0.001)$.

Interviewees who declared that they had dry, oily, or combination skin were also significantly more numerous $(p<0.0001)$ in the "sensitive skin" group than those with normal skin were.

In total, $42 \%$ of people with dry skin, $39 \%$ of people with oily skin, and $28 \%$ of people with combination skin described "sensitive" or "very sensitive" skin. The prevalence of "sensitive" or "very sensitive" skin among the subjects with normal skin was $22 \%$.

\section{Skin Sensitivity According to Climatic and Environmental Factors}

In a series of questions regarding the onset of a rash, tingling, or irritation in the presence of various factors, such as emotional issues, cold, heat, sun, cosmetics, dry air, air-conditioning, water, pollution, and temperature variations, respondents with "sensitive" or "very sensitive" skin responded "yes" more often than others did: in particular, three to two times more often for temperature shifts ( 48.7 vs. $17.1 \%)$, water (14.95 vs. $3.7 \%)$, windy climatic conditions (15.5 vs. $4.9 \%$ ), pollution ( 49.2 vs. $20 \%$ ), airconditioning (5.4 vs. $1.3 \%)$, dry air (29.1 vs. $10.1 \%)$, and cold weather (31.2 vs. $15.6 \%$ ) (Figure 4).

\section{Skin Sensitivity Related to Cosmetics and Food Intake}

Two questions assessed sensitivity to cosmetics and food intake. Respondents with "sensitive" or "very sensitive" skin reported skin sensitivity to cosmetics that was 2 times as high (14.7 vs. 5.5\%, $p<0.001$ ) as that of respondents who reported a greater skin sensitivity associated with food (spices) (19.6 vs. $6.2 \%, p<0.0001)$. 


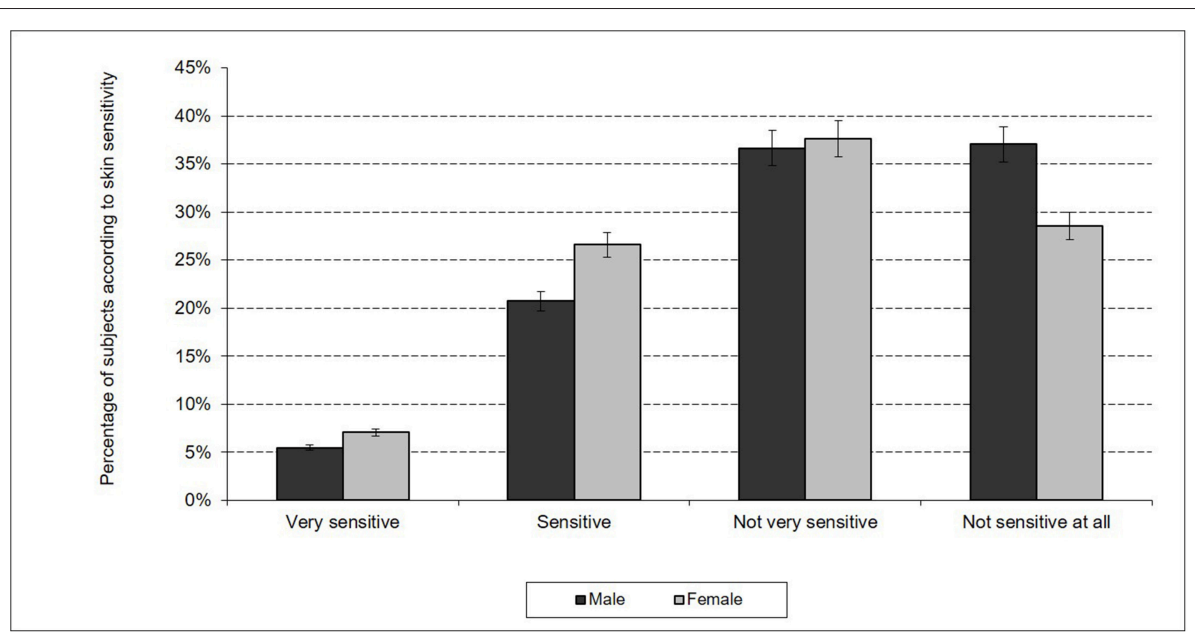

FIGURE 1 | Skin sensitivity in India according sex.

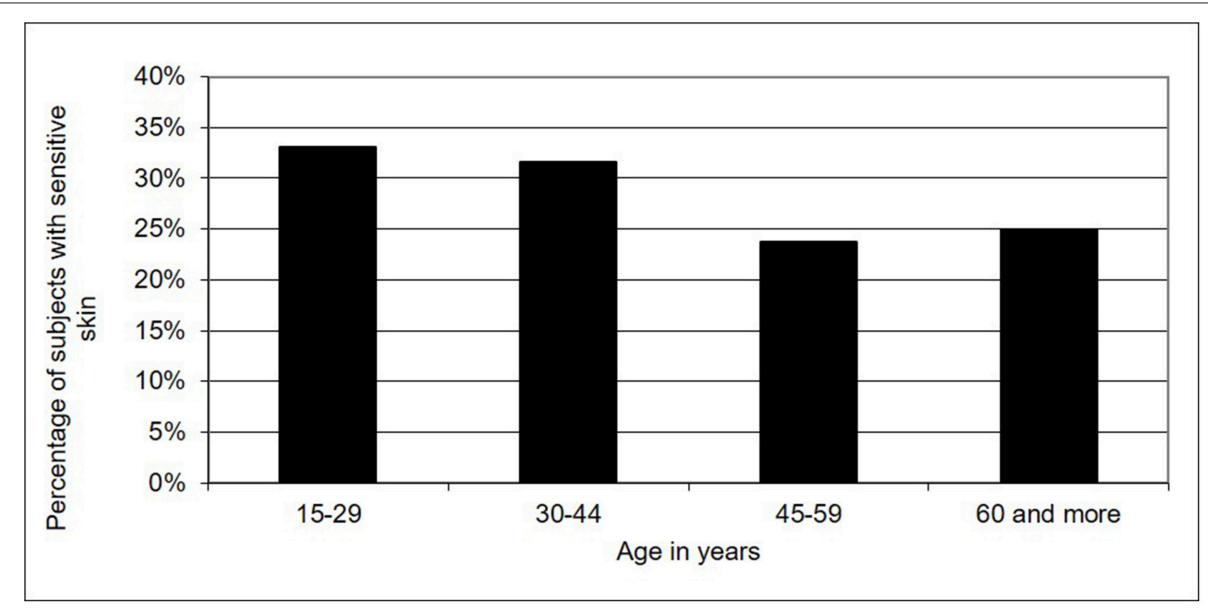

FIGURE 2 | Skin sensitivity in India according age.

\section{History of Consultation With a Dermatologist}

The people in the "sensitive skin" group had previously seen a dermatologist more frequently than those in the "non-sensitive skin" group had ( 15 vs. $2.9 \%, p<0.0001)$.

\section{DISCUSSION}

This study is the first to focus on sensitive skin among Indian people and is of particular interest for two reasons: (i) it was conducted on a representative sample of the Indian population by a recognized polling institute, and (ii) the methodology used was identical to that used in sensitive skin assessment studies conducted in Europe, the US, Brazil and Russia, making it possible to draw certain comparisons.

In the present study, approximately $27.9 \%$ of men and $36.7 \%$ of women reported having "sensitive" or "very sensitive" skin in response to the first question. In comparison, approximately
$52.8 \%$ of Japanese men and $56 \%$ of Japanese women answered "sensitive" or "very sensitive" in response to this same question (12). In total, $32.4 \%$ of the sample of the Indian population (of both sexes) reported having "sensitive" or "very sensitive" skin, representing slightly less than one Indian person in 3 and a significant proportion of the Indian population.

The prevalence of sensitive or very sensitive skin among Indians is very similar to that in Spain, Greece, Portugal, and Brazil but lower than that in other countries (Japan, the US, France, and Italy). Because we used the same methodology to evaluate the frequency of skin sensitivity as in our previous studies (8-13), we could conduct a comparison of the prevalence of skin sensitivity in different countries (Table 1), which showed many differences. It is difficult to determine whether these differences are due to cultural, linguistic, genetic, environmental, or climatic factors.

Geographical differences within the same country were also found in previous studies (8-13). To the hypotheses that we 


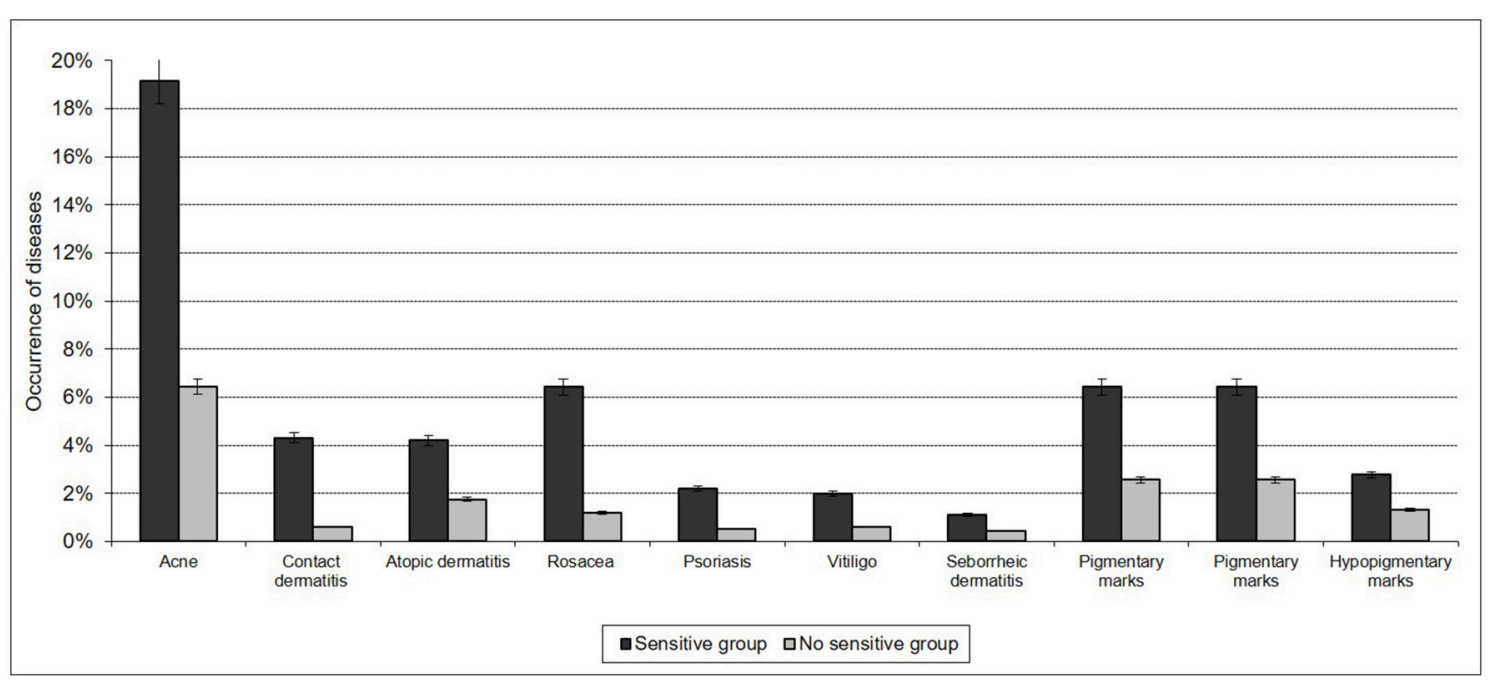

FIGURE 3 | Sensitive skin and reported skin disorders.

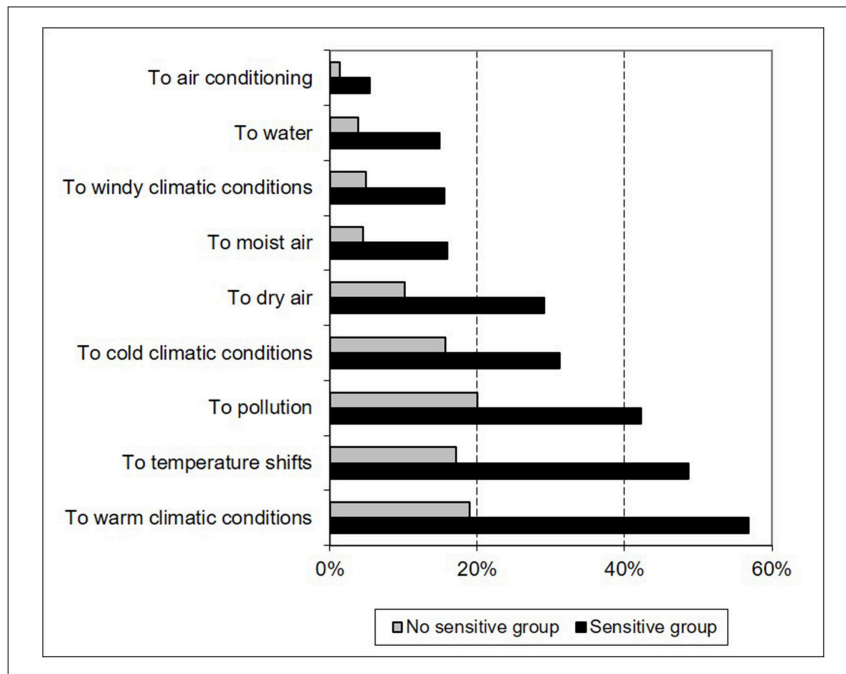

FIGURE 4 | Climatic or environmental factors of sensitive skin reported in patients with sensitive skin.

suggest regarding differences among countries, we could add that different regions within India were defined arbitrarily in the study, which could be a major bias.

To the questions regarding the onset of a rash, tingling, or irritation in the presence of various factors, such as emotional issues, cold, heat, sun, dry air, air-conditioning, water, pollution, and temperature variations. Indian respondents with "sensitive" skin responded "yes" two to three times more often than respondents in the "non-sensitive skin" group did. All of these data confirm that "skin sensitivity" was understood as defined by the medical community $(1-3,5,15)$.

A limitation of this study is that sensitive skin was not diagnosed by doctors, but rather declared by subjects. However, sensitive skin is a condition that is diagnosed through subjective
TABLE 1 | Comparison of frequencies of sensitive skin in different countries [data from this study and from (14)].

\begin{tabular}{lc}
\hline & Sensitive (\%) \\
\hline Japan & 54.5 \\
Italy & 53.0 \\
France & 51.9 \\
USA & 44.6 \\
Russia & 39.7 \\
Germany & 35.6 \\
Brazil & 34.2 \\
Spain & 31.6 \\
Switzerland & 30.8 \\
India & 32.4 \\
Greece & 29.8 \\
Portugal & 27.4 \\
Belgium & 25.8 \\
\hline
\end{tabular}

symptoms reported by subjects (3) and surveys (16) are therefore a suitable method for conducting an epidemiological study on sensitive skin. Moreover, all epidemiological studies on sensitive skins used this method $(7-13,17,18)$. The use of a representative sample of the population is useful for giving extrapolated results (16) although statistics could be eventually overestimated or underestimated (14).

In summary, this is the first study of sensitive skin among the Indian people. This study was conducted on a representative sample of the population by a recognized polling institute. As India counts one billion of persons, and the mean frequency of sensitive skin is $32.3 \%$, we can extrapolate that $\sim 400$ millions of Indians appear to have sensitive or very sensitive skin. This population is probably much larger than that spontaneously complaining of the condition to dermatologists. 
Dermatologists should therefore routinely question their patients about sensitive skin.

\section{AUTHOR CONTRIBUTIONS}

CT and LM contributed conception and design of the study. CT performed the statistical analysis. EB and CT wrote the first

\section{REFERENCES}

1. Frosch P, Kligman A. A method of apraising the stinging capacity of topically applied substances. J Soc Cosmet Chem. (1977) 28:197-209.

2. Thiers H (editor). Peau sensible. In: Les Cosmétiques. 2nd ed. Paris: Masson (1986). p. 266-8.

3. Misery L, Ständer S, Szepietowski JC, Reich A, Wallengren J, Evers AWM, et al. Definition of sensitive skin: an expert position paper from the special interest group on sensitive skin of the international forum for the study of itch. Acta Derm Venereol. 4 (2017) 97:4-6. doi: 10.2340/00015555-2397

4. Farage MA, Katsarou A, Maibach HI. Sensory, clinical and physiological factors in sensitive skin: a review. Contact Dermatitis (2006) 55:1-14. doi: $10.1111 / \mathrm{j} .0105-1873.2006 .00886 . \mathrm{x}$

5. Berardesca E, Farage M, Maibach H. Sensitive skin: an overview. Int J Cosmet Sci. (2013) 35:2-8. doi: 10.1111/j.1468-2494.2012.00754.x

6. Misery L, Loser K, Ständer S. Sensitive skin. J Eur Acad Dermatol Venereol. (2016) 30 (Suppl. 1):2-8. doi: 10.1111/jdv.13532

7. Willis CM, Shaw S, De Lacharrière O, Baverel M, Reiche L, Jourdain R, et al. Sensitive skin: an epidemiological study. Br J Dermatol. (2001) 145:258-63.

8. Misery L, Myon E, Martin N, Verrière F, Nocera T, Taieb C. [Sensitive skin in France: an epidemiological approach]. Ann Dermatol Venereol. (2005) 132:425-9.

9. Misery L, Boussetta S, Nocera T, Perez-Cullell N, Taieb C. Sensitive skin in Europe. J Eur Acad Dermatol Venereol. (2009) 23:376-81. doi: $10.1111 / j .1468-3083.2008 .03037 . x$

10. Misery L, Myon E, Martin N, Consoli S, Boussetta S, Nocera T, et al. Sensitive skin: psychological effects and seasonal changes. JEur Acad Dermatol Venereol. (2007) 21:620-8. doi: 10.1111/j.1468-3083.2006.02027.x

11. Misery L, Sibaud V, Merial-Kieny C, Taieb C. Sensitive skin in the American population: prevalence, clinical data, and role of the dermatologist. Int $J$ Dermatol. (2011) 50:961-7. doi: 10.1111/j.1365-4632.2011.04884.x

12. Kamide R, Misery L, Perez-Cullell N, Sibaud V, Taïeb C. Sensitive skin evaluation in the Japanese population. J Dermatol. (2013) 40:177-81. doi: $10.1111 / 1346-8138.12027$ draft of the manuscript. All authors contributed to manuscript revision, read, and approved the submitted version.

\section{FUNDING}

Pierre Fabre Group provided funds to perform the Survey. Pierre Fabre Group participated in study design and data collection.

13. Taieb C, Auges M, Georgescu V, Perez Cullell N, Miséry L. Sensitive skin in Brazil and Russia: an epidemiological and comparative approach. Eur J Dermatol. (2014) 24:372-6. doi: 10.1684/ejd. 2014.2367

14. Wolkenstein P, Grob J-J, Bastuji-Garin S, Ruszczynski S, Roujeau J-C, Revuz J, et al. French people and skin diseases: results of a survey using a representative sample. Arch Dermatol. (2003) 139:1614-9; discussion 1619. doi: 10.1001/archderm.139. 12.1614

15. Muizzuddin N, Marenus KD, Maes DH. Factors defining sensitive skin and its treatment. Am J Contact Dermat. (1998) 9:170-5.

16. Hansen M, Hurwitz W, Madow W. Sample Survey Methods and Theory, Vol. 1. New York, NY: John Wiley \& Sons (1993).

17. Jourdain R, de Lacharrière $O$, Bastien P, Maibach HI. Ethnic variations in selfperceived sensitive skin: epidemiological survey. Contact Dermatitis (2002) 46:162-9. doi: 10.1034/j.1600-0536.2002.460307.x

18. Guinot C, Malvy D, Mauger E, Ezzedine K, Latreille J, Ambroisine $\mathrm{L}$, et al. Self-reported skin sensitivity in a general adult population in France: data of the SU.VI.MAX cohort. J Eur Acad Dermatol Venereol. (2006) 20:380-90. doi: 10.1111/j.1468-3083.2006. 01455.x

Conflict of Interest Statement: CT is employee of the Pierre Fabre Group. LM has been or is currently a consultant for Bioderma, Clarins, Expanscience, Johnson \& Johnson, L'Oréal, Nestlé Skin Health, Pierre Fabre, Solabia, and Uriage. EB was speaker for Bioderma.

Copyright (C) 2019 Brenaut, Misery and Taieb. This is an open-access article distributed under the terms of the Creative Commons Attribution License (CC BY). The use, distribution or reproduction in other forums is permitted, provided the original author(s) and the copyright owner(s) are credited and that the original publication in this journal is cited, in accordance with accepted academic practice. No use, distribution or reproduction is permitted which does not comply with these terms. 